\title{
Contribution of suction on the stability of reinforced-soil retaining wall
}

\author{
Nurly Gofar ${ }^{1, *}$ and Hanafiah ${ }^{2}$ \\ ${ }^{1}$ School of Civil and Environmental Engineering, Nanyang Technological University, 50 Nanyang \\ Avenue, Singapore 639798 \\ ${ }^{2}$ Department of Civil Engineering, Faculty of Engineering, Sriwijaya University, Palembang 30139, \\ Indonesia
}

\begin{abstract}
Existing design methods of a reinforced-soil retaining wall were established for walls with cohesionless soil backfill. However, local soil has been used widely in the construction of such a wall for economic reasons. Laboratory and numerical studies have pointed out the merit of using cohesive backfill in association with geosynthetic reinforcement. Since the compacted soil was in an unsaturated condition during the construction of the reinforced wall, the apparent cohesion derived from both soil mineralogy and suction could contribute to the stability of the wall. This paper considers methods to include the suction contribution to the existing design guidelines based on slope stability analysis, i.e. simplified method and simplified stiffness method. The analyses were carried out on a case study of geosynthetics reinforced soil retaining wall. Results show that the contribution of suction as part of cohesion existing in the cohesive backfill could be considered for the stability analysis of reinforced soil retaining walls using the available design guidelines.
\end{abstract}

\section{Introduction}

Geosynthetics reinforced soil retaining walls have been used as an alternative system for slope stabilization, conventional retaining walls, embankments, and abutment walls. The system consists of compacted backfill, reinforcing element, and facing unit [1]. The system requires a minimum amount of material and equipment for construction and provides a flexible structure that is more tolerable to settlement or movement. Because of the attractiveness of the system, analysis methods that would help design them safely and economically are needed. Existing design guidelines e.g. AASHTO [2] and FHWA [3] have stringent requirements for selecting backfill materials for the construction of reinforced soil retaining walls. According to these guidelines, freely drainable and well-graded granular materials should be used as backfill. The maximum percentage of fines (i.e. passing 0.075 $\mathrm{mm}$ sieve) in the backfill should not exceed $15 \%$ and the plasticity index should remain below $6 \%$ for walls and below $20 \%$ for slopes. Koerner and Koerner [4] reported that, when these requirements are followed, the soil backfill would take up as high as 50 to $75 \%$ of the

* Corresponding author: hanafiah_dr@yahoo.com.sg 
total cost of the wall construction. Thus, the possibility of using locally available soil as the backfill material is of significant economic advantages.

Despite the increasing number of geosynthetic reinforced soil retaining walls constructed using local soil, the design guidelines still do not consider the contribution of the soil's cohesion on the stability of the wall for two reasons. First, it had been previously assumed that the maximum bond between cohesive soil and reinforcement would be controlled by the undrained shear strength of the cohesive soil. Thus, in the presence of cohesion, the use of soil reinforcement would offer no real advantage. On the other hand, the use of cohesive soil as backfill material has been credited as the cause of many failures of conventional retaining walls as well as reinforced-soil walls. Several case studies [e.g. 5, $6,7]$ have shown that many failures of reinforced-soil walls were associated with cohesive backfill. However, a further study conducted by [7] on 171 failed geosynthetics reinforced walls, concluded that the main reason for such failures was not the properties of the backfill material, but the improper drainage in the system. The accumulation of water within the reinforced zone could increase the total force against the wall, significantly resulting in large wall deformation. In addition, wetting of the soil can cause reduction in soil shear strength and interfacial shear resistance as well as intensifying the creep deformation of the soil. The main causes of water accumulation and wetting of the backfill soil are rainfall infiltration, rise of ground water table and seepage from the back of reinforced zones. Thus, the backfill soil should be protected from rainfall infiltration. The drainage system and utilities should be shifted out at suitable distances from the reinforced soil zone.

The performance of the reinforced soil retaining wall was also related to the type of geosynthetics used as reinforcing element. Studies on the use of cohesive soils as backfill material with geotextile reinforcement have been conducted by researchers. For example, through several case histories, [8] showed that the use of nonwoven geotextile could facilitate internal drainage in the reinforced soil zone comprising less permeable backfills even after subjected to heavy rainfall or rising ground water conditions. The internal drainage could lead to an improved stability by dissipating pore-water pressures during construction or precipitation events [9]. Furthermore, capillary barrier condition could prevail when rainfall infiltration reaches the interface between the reinforced soil and the first layer of geotextile reinforcement, limiting rainfall infiltration into the reinforced zone [10]. In addition, [11] showed that the nonwoven geotextiles can help accelerate the fill consolidation and increase the soil's shear strength as well as the interface adhesion between the backfill soil and the geotextile. Thus, the combination of geotextile (especially the non-woven type) with cohesive backfill offers an important cost savings in the construction of reinforced-soil retaining walls. Creep is a potential problem for polymeric reinforcement such as geotextile; thus, long term performance of the structure needs to be evaluated. Several studies $[12,13,14,15]$ were performed on retaining walls with geogrid reinforcement. Since geogrid does have drainage capability, additional measures were considered in the study. For example [12] used a chimney drain, [13] used an in-plane drainage inside the geogrids, while [14] utilized a capillary barrier system. Results showed that the geogrids reinforced wall performed well when combined with the drainage system to protect backfill soil from excess pore-water pressure resulting from rainfall infiltration as well as seepage from rising of the ground water table.

Based on the preceding discussion, the local materials with large fine contents have been used successfully as backfill for geosynthetic-reinforced-soil walls. Thus, the contribution of intrinsic cohesion should be considered in the design and stability analysis of the reinforced soil retaining wall [15]. For unsaturated soil, the cohesion of soil is derived from soil's mineralogy (c') and matric suction $(\psi)[16]$ as in Eq. 1:

$$
c=c^{\prime}+\psi \tan \phi^{b}
$$


The effective cohesion ( $\left(c^{\prime}\right)$ is the intercept of the extended Mohr-Coulomb failure envelope with the shear stress axis at a specific matric suction, while $\phi^{b}$ is an angle indicating the rate of increase in shear strength with respect to a change in matric suction. At zero matric suction, the intercept can be referred to as the total cohesion which is derived from the soil's mineralogy.

Three approaches could be used to evaluate the contribution of suction on the stability of reinforced soil retaining walls. First, assuming the reinforced soil wall as a steep slope, the load resisted by a reinforcing element can be analysed by performing slope stability analysis and setting the failure plane inside the reinforced zone. Limit equilibrium program SLOPE/W [17] was adopted for the stability analysis and calculation of the load resisted by reinforcement. The stability analysis of reinforced slope, as presented in [1], was used in this study as Method A. Second, as a retaining wall, the stress transferred to reinforcing element can be approached theoretically by integrating the formulation of lateral earth pressure for cohesive soil in the simplified method outlined in AASHTO and FHWA [2, 3]. The effect of cohesion on the lateral earth pressure distribution with depth is considered for the calculation of load resisted by each reinforcement layer. The analysis using this simplified method is referred to as Method B in this study. Third, empirical studies carried out by Miyata $[18,19]$ through nine geosynthetics and eighteen steel reinforced wall cases with $\mathrm{c}-\phi$ soil showed that reinforced walls with cohesive soil backfill can stand a larger deformation as compared to walls with cohesionless soil backfill. The empirical formulation for the effect of cohesion was then adopted in the stiffness method as presented in [20]; which was later modified by Allen and Bathurst [21]. The method was termed as simplified stiffness method, referred to as Method C in this current study.

This paper presents the study on the effect of cohesion on the stress transferred to the reinforcing element using Methods A, B and C. Analyses were carried out on a typical reinforced soil retaining wall described in [21]. The wall was $3.6 \mathrm{~m}$ high, sloping at $70^{\circ}$ to horizontal, and reinforced by six geotextile layers. The reinforced backfill was cohesive soil with total cohesion of $15 \mathrm{kPa}$. A parametric study was performed for a range of suctions from 10 to $50 \mathrm{kPa}$ with intervals of $10 \mathrm{kPa}$.

\section{Theoretical background}

\subsection{Stability of reinforced-soil retaining wall}

The stability of reinforced soil retaining walls is usually evaluated with respect to the external and internal stability. The external stability of the reinforced soil retaining wall is verified by considering a rigid gravity structure. Potential external failure mechanisms considered for reinforced-soil walls include: sliding on the base, bearing capacity failure, and overall slope stability. The reinforced soil retaining wall is usually considered as a free-standing wall because it is placed on the ground surface with a small embedment. Overturning stability and excessive settlements are rarely an issue for reinforced soil retaining walls because the wall cannot mobilize bending due to inherent flexibility [1]. In the design of a free-standing wall, normally the base of the wall $B$ is designed as $2 / 3$ of the height of the wall $(H)$ in order to maintain sufficient bearing capacity. Other geometries should be designed based on the site conditions. The external stability is usually calculated based on limit equilibrium methods, where the procedures could be found in [1].

The internal stability of the retaining wall is evaluated by comparing the stress generated in each reinforcing layer with the resistance provided by the tensile strength of the reinforcement and the friction between the soil and the reinforcement. For the evaluation of tensile failure of the geosynthetic layer, the maximum tensile stress developed 
in the reinforcement $\left(T_{\max }\right)$ is compared to the ultimate strength of the reinforcement $\left(T_{u}\right)$. The available factor of safety $\left(F_{o} S_{\text {tensile }}\right)$ should be greater than the material reduction factors related to installation damage of the reinforcement $\left(F_{C}\right)$, creep effects $\left(F_{D}\right)$, and environmental effects $\left(F_{S}\right)$ over the required life of the reinforcement $[1,3]$ as in Eq. 2:

$$
\text { FoS } S_{\text {tensile }}=\left(T_{u} / T_{\max }\right) \geq\left(F_{C} \times F_{D} \times F_{S}\right)
$$

The internal stability of reinforced soil retaining walls resulting from frictional forces developed between the soil and the reinforcement. The evaluation of pull-out resistance of the geogrids requires the definition of local failure plane inside the reinforced soil zone. The length of reinforcement extending beyond the failure plane is the available anchorage length that resists the pull-out $\left(L_{a}\right)$. The pull-out resistance depends on the overburden pressure $\left(\sigma_{v}^{\prime}\right)$, the anchorage length $\left(L_{e}\right)$, and the mechanism of stress transferred between the soil and the reinforcement. The stress transfer mechanism between the backfill soil and the reinforcement depends on the type of reinforcing element [3]. For geotextile and geogrid reinforcement with opening $>d_{50}$ of the reinforced soil, the stress transfer could be estimated as $\alpha \times 2 / 3 \tan \phi^{\prime}$ for which $\alpha$ is a scale effect correction factor depending on the type of reinforcement, and $\phi^{\prime}$ is the angle of internal friction of the reinforced soil. The required anchorage length of geosynthetics reinforcement $\left(L_{e}\right)$ is as follows:

$$
L_{e}=\left(\sigma_{v}^{\prime} \times 2 / 3 \tan \phi_{r} \times \alpha \times A\right) / \tau_{\max }
$$

Thus, the factor of safety with respect to pull-out is:

$$
F_{O} S_{\text {pullout }}=\left(L_{a} / L_{e}\right) \geq 1
$$

\subsection{Estimation of stress transferred to reinforcing element}

Stability analysis of steep reinforced slopes could be analysed using Bishop's simplified method [22] for an assumed failure plane. In this case, each layer of reinforcement can be represented by a concentrated force applied to the base of the slice as shown in Fig. 1. In this study, the stress transferred to the reinforcing element was calculated through the slope stability program SLOPE/W.

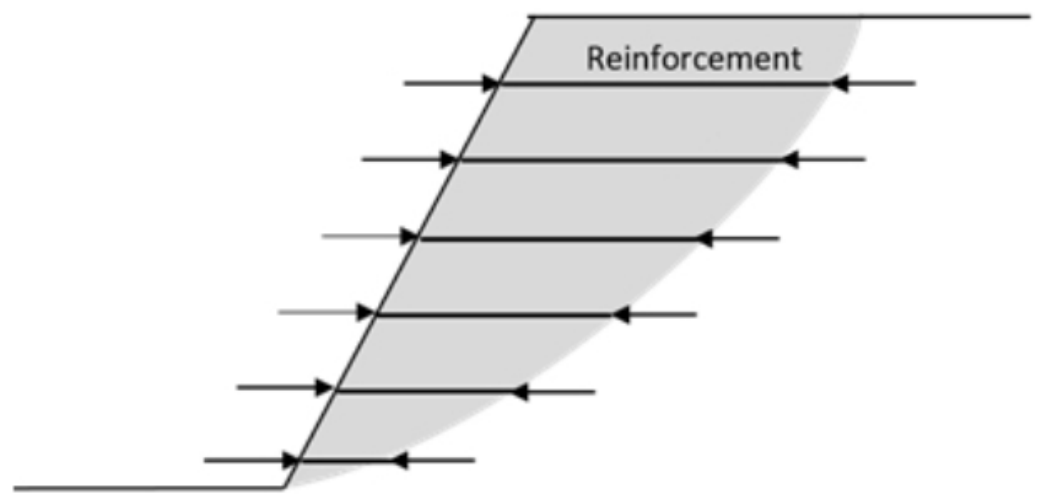

Fig. 1. Reinforcement force used in the internal stability analysis of reinforced soil slope using [23].

When flexible reinforcing elements such as geosynthetics are used in the reinforced-soil retaining wall, the wall could move sufficiently before failure, thus active earth pressure is used in the design and stability analysis [2, 3]. The coefficient of Rankine's active lateral earth pressure for vertical walls is given in Eq. 5: 


$$
K_{a}=\tan ^{2}\left(45-\phi^{\prime} / 2\right)
$$

For near vertical or battered walls, the coefficient of lateral earth pressure was calculated using Coulomb's formula. The horizontal components of the coefficient of active lateral earth pressure for vertical walls is given in Eq. 6:

$$
K_{a b h}=\cos ^{2}\left(\phi^{\prime}-\omega\right) /\left(\cos ^{2} \omega(1+\sin \phi \% \cos \omega)\right)
$$

where $\phi$ ' is as defined previously and $\omega$ is the wall face batter measured from vertical. The horizontal pressure against the wall with cohesionless backfill soil is:

$$
\sigma_{h}^{\prime}=\sigma_{v} K_{a}
$$

where $\sigma_{v}^{\prime}$ is the vertical stress at a depth. The presence of cohesion in the backfill soil reduces the active earth pressure. The horizontal earth pressure against the wall $\left(\sigma_{h}\right)$ with cohesive backfill is as follows:

$$
\sigma_{h}^{\prime}=\sigma_{v}^{\prime} K_{a}-\left(2 c \sqrt{ } K_{a}\right)
$$

where $c$ is as defined in Eq. 1. If both effective cohesion and matric suction are constant with depth, the active pressure distribution is translated to the left, thus the pressure at the upper part of the wall becomes negative. Fig. 2 shows the breakdown of the active pressure distribution in unsaturated soil into its three stress distribution components. The stress transferred from soil to the reinforcing element could be calculated for each reinforcement layer based on the pressure distribution presented in this figure. However, only positive pressure was considered in the analysis adopted in this study.

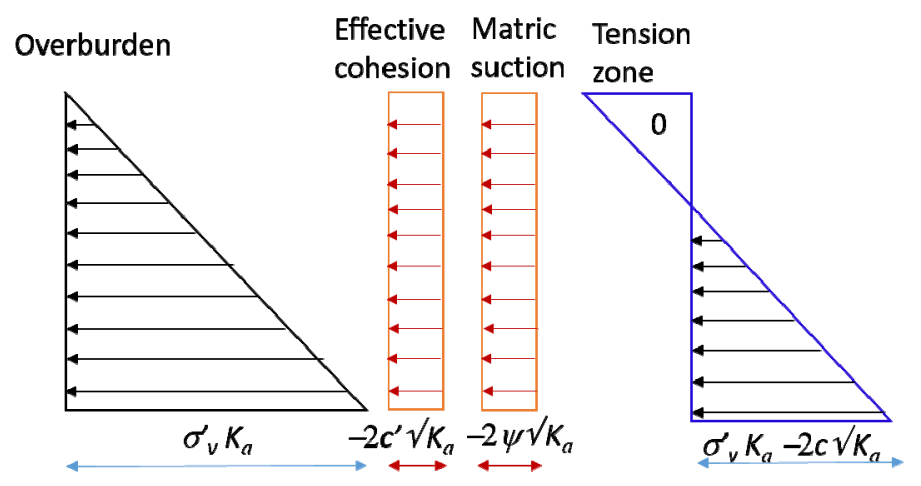

Fig. 2. Active earth pressure distribution in unsaturated soil if suction is constant with depth [17].

The maximum tensile or pull-out force $\left(T_{\max }\right)$ resisted by a reinforcing element is the integration of horizontal stress within the tributary area of the reinforcement layer. For geosynthetic reinforcement the tributary area is equal to the vertical distance between two reinforcing elements $\left(S_{v}\right)$ :

$$
T_{\max }=\sigma_{h}^{\prime} S_{v}
$$

The simplified method [2, 3] did not consider the effect of various components of reinforced soil retaining walls such as the stiffness of reinforcing elements, type of facing and the global stiffness of the wall itself. Some efforts have been made to include the effect of these factors on the design of reinforced soil retaining walls [21, 22, 23]. In this study, 
the effect of cohesion in the simplified method was included by considering the cohesion in the calculation of horizontal stress as shown in Eq. 8.

Through years of study on the performance of well-documented and monitored fullscale walls, Bathurst et al. [20] proposed an empirical formulation to predict the stress transferred to a reinforcing element. They showed that the stress transferred to the reinforcing element depends on many factors such as global and local reinforcement stiffness, facing stiffness and face batter as well as cohesion. The method was calibrated using databases of case studies and presented in a similar form as the simplified method [2]. The modified stiffness method was then referred to as simplified stiffness method [21]. The maximum tensile stress in the reinforcement $\left(T_{\max }\right)$ is empirically derived from reinforcement strain measurements from full-scale walls at working stress conditions and converted to load based on the reinforcement modulus:

$$
T_{\max }=S_{v}\left[\gamma_{r} H D_{\text {tmax }}+\left(H_{\text {ref }} / H\right) \gamma_{r} S\right] K_{a v h} \Phi_{f b} \Phi_{g} \Phi_{f s} \Phi_{\text {local }} \Phi_{c}
$$

where $K_{a v h}$ is the active earth pressure coefficient; $\gamma_{r}$ and $\gamma_{f}$ are the unit weight of the reinforced soil and the soil surcharge; $H$ is the wall height; $S$ is the equivalent height of uniform surcharge pressure; $H_{r e f}$ is reference height $=6 \mathrm{~m} ; S_{v}$ is the vertical spacing between two reinforcing layers, and $D_{\text {tmax }}$ is the load distribution factor; defined as the ratio between the tensile stress developed at a specified depth of reinforcement $\left(T_{\max }\right)$ to the maximum tensile stress developed in the entire wall $\left(T_{m x m x}\right)$. For the battered wall $\left(\omega>20^{\circ}\right)$ with $H \leq 9 \mathrm{~m}$ used in this study, the $D_{\text {tmax }}$ value varies from 0.12 to 1 for $z / H$ (the ratio of reinforcement depth to the height of the reinforced wall) between 0 and 0.3 ; and is constant for $z / H$ between 0.3 and 1 . The $\Phi_{g}, \Phi_{l o c a l}, \Phi_{f s}, \Phi_{f b}$ are influence factors related to the effects of global and local reinforcement stiffness, wall facing stiffness and wall face batter, respectively. The formulation of each influence factor is presented in [20]. The most important factor evaluated in this study is the cohesion factor $\Phi_{c}$. The effect of cohesion was first developed by [18, 19] and modified by [21] in the following form:

$$
\Phi_{c}=\mathrm{e}^{\lambda \mathrm{c} / \gamma \mathrm{H}} \quad \text { where } 0 \geq \Phi_{c} \geq 1
$$

where $\lambda$ is the cohesion coefficient $=-16 ; c$ is the cohesion of the reinforced soil. The cohesion can be derived from soil mineralogy or apparent cohesion resulting from matric suction or negative pore-water pressure. In this method, the cohesion factor is only applicable for soil with plasticity index $(\mathrm{PI})>6$.

\section{Case study}

A case study of a steep soil retaining wall reinforced with geotextile, shown in Fig. 3, was used in the study. The wall was $3.6 \mathrm{~m}$ high, sloping at $70^{\circ}$ to the horizontal and is reinforced by six reinforcing layers. The length of the reinforcing layers was $2.6 \mathrm{~m}$. The properties of the soil and the geotextile reinforcement are presented in Fig. 3. A baseline case was needed to have the basis for comparison in terms of maximum load transferred to reinforcing elements and available anchorage length. Thus, the active Coulomb failure plane (Fig. 4) for battered wall was used as the failure plane for all analyses (Methods A, B and $\mathrm{C}$ ). The analysis of the baseline case was performed assuming that the reinforced soil has no cohesion $(c=0)$. External stability analysis indicated that the wall is safe with a factor of safety of 2.2, 9.72, and 7.16 against sliding, overturning and bearing capacity of the foundation soil respectively. The overall stability of the wall analysed using Bishop's method integrated in [17], resulted in a minimum factor of safety of 2.57 (Fig. 5a). Analysis of load transferred to reinforcing element was first carried out using Method A [18] by 
assuming a fully specified failure plane following the Coulomb failure plane shown in Fig. 4. The factor of safety for local slope failure for the baseline case $(c=0)$ was 1.49 . Fig. $5 \mathrm{~b}$ shows that, for this condition, the length of reinforcement is sufficient with critical condition at the topmost layer. These factors of safety indicated that the wall was safe for the most critical condition $(c=0)$.

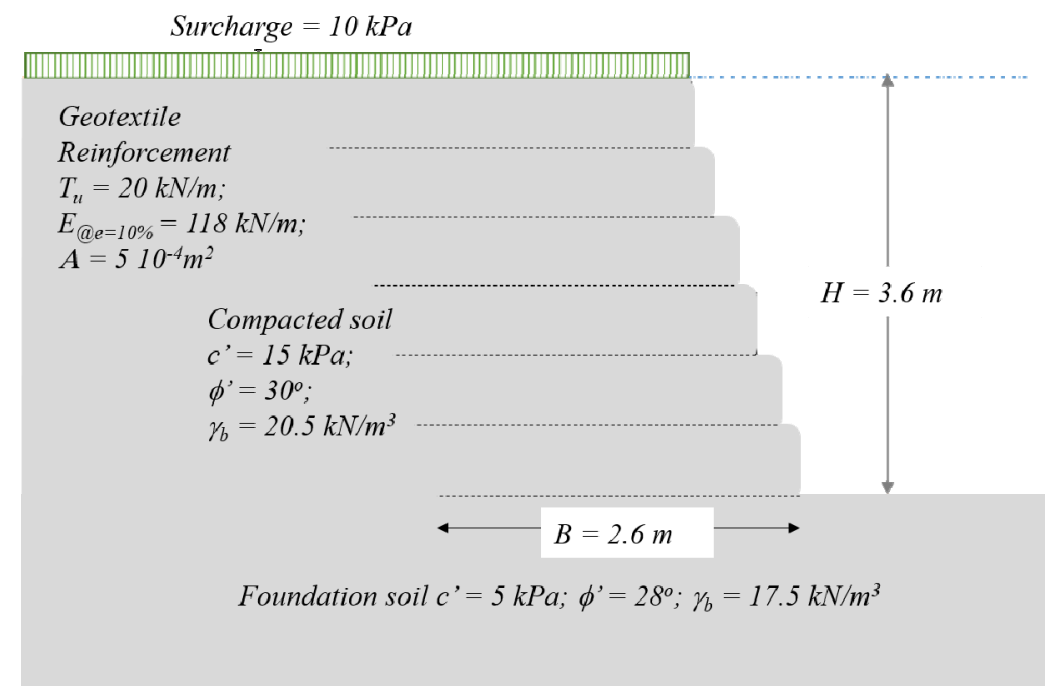

Fig. 3. Case study of reinforced-soil retaining wall used in this study.

Fig. 4. Definition of failure plane for soil wall reinforced with extensible reinforcement [3].
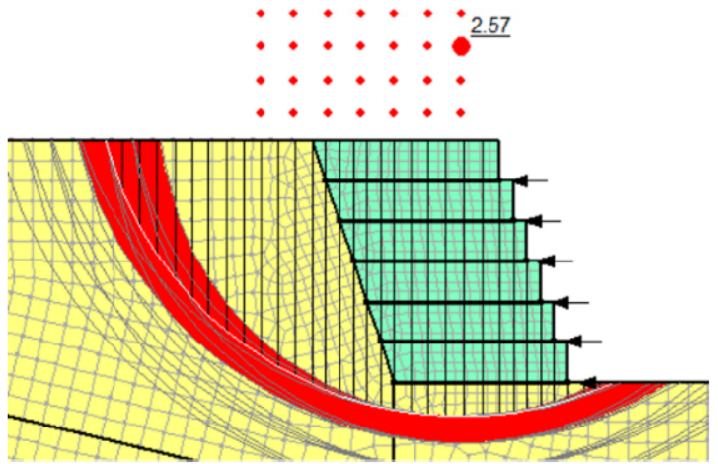

(a) Overall stability

$$
\begin{aligned}
& \text { Coulomb } \\
& \text { failure plane } \beta=20^{\circ} \\
& \qquad \begin{array}{c}
\left(45+\phi^{\prime} / 2\right)
\end{array}
\end{aligned}
$$


The maximum tensile stress / pull-out force calculated using Methods A, B and C for the baseline case is shown in Fig. 6. The figure indicated that all methods gave comparable results at higher reinforcement layers. However, the results differed in the lower layer. Method B showed that the tensile force is linearly increasing with depth because the method considered the tensile force as the function of overburden pressure. Method B considered the tensile force that developed in the reinforcing element depends of the interslice force, while method $\mathrm{C}$ considers the stiffness of the wall including the reinforcing element and wall facing.

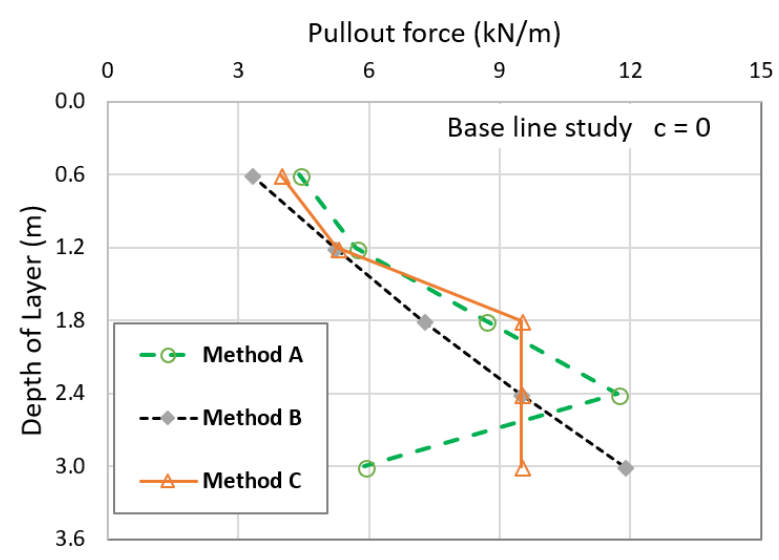

Fig. 6. Tensile / Pull- force in each reinforcing element calculated using Methods A, B, and C.

\section{Effect of suction}

A parametric study was performed for the soil with actual properties of reinforced soil retaining walls used in this study i.e. with effective cohesion of $15 \mathrm{kPa}$ and variable suction from 10 to $50 \mathrm{kPa}$. Since no data was available, the $\phi^{b}$ value of the compacted soil was assumed to be $2 / 3$ of $\phi^{\prime}=20^{\circ}$, thus the total cohesion used in this parametric study is from 15 to $33.2 \mathrm{kPa}$ with intervals of $3.6 \mathrm{kPa}$. The properties used in the parametric study is summarized in Table 1.

Analyses on the effect of suction on maximum force transferred to reinforcing elements were performed using SLOPE/W [Method A], simplified method [Method B] and simplified stiffness method [Method C]. The effect of suction using the methods are presented in normalized form i.e. the Tensile / Pull-out force for a certain cohesion value divided by the baseline case $(c=0)$. Fig 7 shows the effect of effective cohesion on the tensile or pull-out force in the reinforcing element. The figure indicated that the effect of suction is quite significant. The most significant effect was captured by Method $\mathrm{C}$ while Method A gave a milder effect as compared to Method A and B. Therefore, the contribution of suction as part of cohesion existing in the cohesive backfill could be considered when using the simplified design method [2, 3] by adopting Rankine's horizontal pressure distribution in the retaining wall for active condition.

Table 1. Suction values and the corresponding total cohesion used in this study.

\begin{tabular}{|c|c|c|c|c|c|c|c|}
\hline Suction, $\psi(\mathbf{k P a})$ & 0 & 0 & 10 & 20 & 30 & 40 & 50 \\
\hline $\begin{array}{c}\text { Total cohesion } \\
\mathbf{c}=\mathbf{c}^{\prime}+\psi \tan \phi^{\mathbf{b}}(\mathbf{k P a})\end{array}$ & 0 & 15 & 18.6 & 22.3 & 25.8 & 29.6 & 33.2 \\
\hline
\end{tabular}




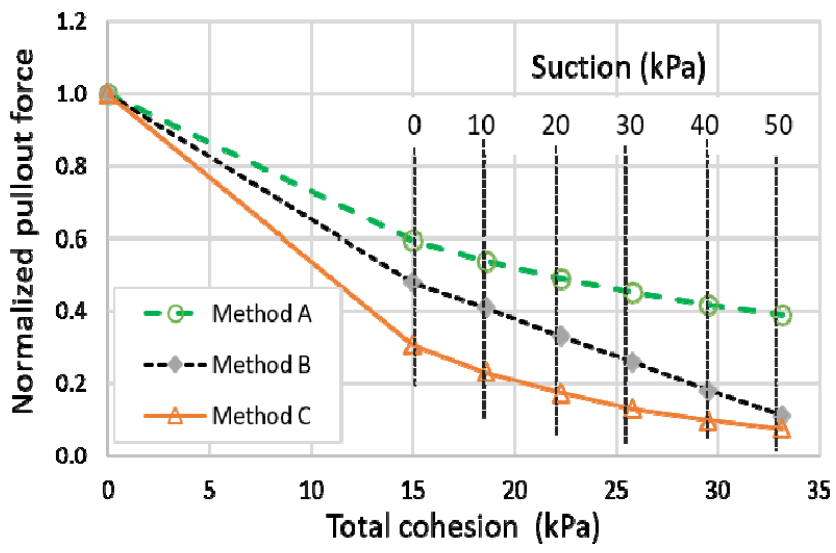

Fig 7. Effect of suction on the Normalized Tensile / Pull- force in each reinforcing element

The contribution of suction on the local stability of reinforced soil slopes was analysed using SLOPE/W [Method A]. The result presented in Fig. 8 indicated that the suction contributes significantly to the local stability of the reinforced soil wall. The $F o S$ for the base line case $(c=0)$, actual soil properties $(c=15 \mathrm{kPa})$ and suction $(\psi=50 \mathrm{kPa})$ was 1.49 , 2.41 and 3.67 respectively. Thus, suction existing in the compacted backfill soil should be maintained by protecting the wall from rainfall infiltration, rise of the ground water table and seepage from the back of the reinforced zone.

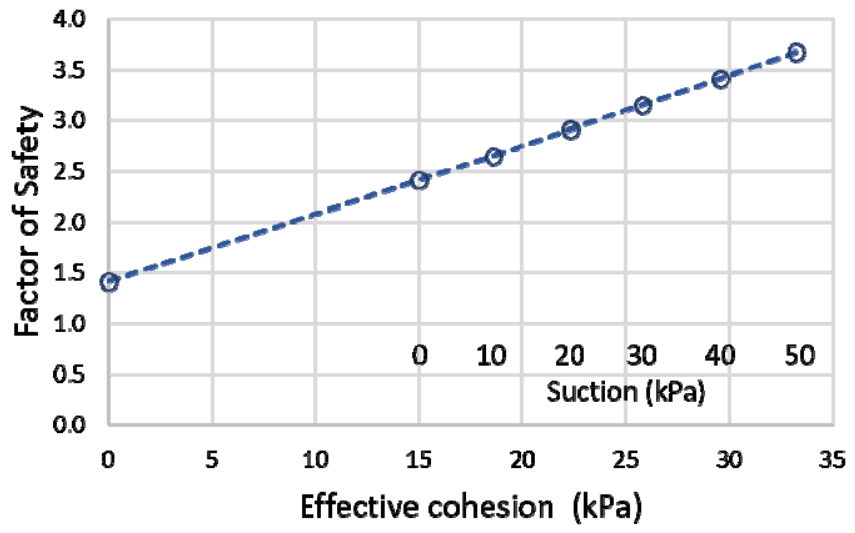

Fig. 8. Effect of suction on the internal stability of reinforced soil retaining wall.

\section{Conclusions}

The contribution of suction (as a component of total cohesion in cohesive soil backfill) on the stability of reinforced soil retaining walls was studied by considering the wall as a reinforced soil slope (Method A) or as a reinforced soil retaining wall (Method B and C). The following conclusions are derived from this study:

1. All methods suggested that the presence of suction decreases the maximum force resisted by the reinforcing element. However, methods $\mathrm{A}, \mathrm{B}$, and $\mathrm{C}$ showed different degrees of influence of suction on the stress transferred to the reinforcing element. Based on the normalized pull-out force, the biggest contribution of suction was predicted by Method $\mathrm{C}$ and the smallest contribution was predicted by Method A. 
2. The contribution of cohesion on the current design guidelines (Method B) by adopting Rankine's horizontal pressure distribution in the retaining wall for active condition provides a more reasonable effect as compared to the simplified stiffness method (Method C). Therefore, the contribution of suction as part of cohesion existing in the cohesive backfill could be considered for the stability analysis of reinforced soil retaining walls using the available design guidelines.

3. There is an increase in the local stability of the reinforced soil retaining wall due to suction. However, in order to preserve the contribution of the suction in the stability of the wall, the compacted backfill soil should be maintained by protecting the wall from rainfall infiltration, rise of the ground water table and seepage from the back of the reinforced zone.

\section{References}

1. R.M. Koerner, R.M. Designing with Geosynthetics, 5th ed. (2005)

2. AASHTO. Standard Specifications for Highway Bridges, 17th ed. (2009).

3. R.R.Berg, B.R.Christopher, N.C.Samtani, FHWA-NHI-10-024FHWA GEC 011 (2009).

4. R.M. Koerner, G.R. Koerner, J. Geoengineering 6 (1) (2011).

5. S.M.B. Helwany, G. Reardon, J.T.H. Wu. Geotextiles \& Geomembranes. 17(1) (1999).

6. C. Yoo, H.Y. Jung, ASCE J. Geotech. \& Geoenv. Eng. 132(12) (2006).

7. R.M. Koerner, G.R. Koerner, Geotextiles \& Geomembranes 40 (2013).

8. J.K. Mitchell, J.G. Zornberg, Geosynthetic Int. 2 (1) (1995).

9. F.H.M. Portelinha, J.G. Zornberg, Geotextiles \& Geomembranes 45 (2017).

10. G. Siemens R.J. Bathurst, Geotextiles and Geomembranes, 28(5) (2010).

11. H.I. Ling, F. Tatsuoka, ASCE J. Geotech. Engng. 120(7) (1994).

12. B.V.S. Viswanadham, H.R. Razeghi, J. Mamaghanian, C.H.S.G. Manikumar, Geotextile \& Geomembranes 45 (2017).

13. Y. Kang, B. Nam, J.G. Zornberg, Y. Cho, KSCE J. Civil Eng. 19(3) (2015).

14. H. Rahardjo, N. Gofar, A. Satyanaga, Invited paper Proc. $11^{\text {th }} I C G$-Seoul (2018).

15. J.M. Clancy, P.J. Naughton, Advances in Transportation Geotechnics (2008).

16. D.G. Fredlund, H. Rahardjo, M.D. Fredlund, M D. Unsaturated Soil Mechanics in Engineering Practice. John Wiley \& Sons, Inc. (2012).

17. Geo-Slope International Ltd. SLOPE/W for Slope Stability Analysis (2012).

18. Y. Miyata, R.J. Bathurst, Soils and Foundations. 52 (2012).

19. Y. Miyata, R.J. Bathurst R.J. Can. Geotech. J. 44 (2) (2007).

20. R.J. Bathurst Y. Miyata, A. Nernhim, T.M. Allen, Geosynthetic Int. 15 (4) (2008).

21. T.M. Allen, R.J. Bathurst, ASCE J. Geotech. \& Geoenv. Eng. 141(11) (2015).

22. N. Gofar, Modeling of boundary applied load transmission on Geosynthetics reinforced structures. PhD Thesis. Purdue University (1994)

23. S.G. Wright, J.M. Duncan, J.M. Transportation Research Record 1330 (1991). 